\title{
Effect of dextrans on cryopreservation of goat cauda epididymal spermatozoa using a chemically defined medium
}

\author{
C. N. Kunduํ, J. Chakrabarty ${ }^{1}$, P. Dutta ${ }^{1}$, D. Bhattacharyya ${ }^{2}$, \\ A. Ghosh ${ }^{3}$ and G. C. Majumder ${ }^{1 *}$ \\ ${ }^{1}$ Indian Institute of Chemical Biology, 4 Raja SC Mullick Road, Jadavpur, \\ Calcutta 700 032, India; ${ }^{2}$ Advanced Centre of Cryogenic Research, Jadavpur University, \\ Jadavpur, Calcutta 700 032, India; and ${ }^{3}$ Drug Research and Development Centre, \\ 1078 Jessore Road, Calcutta 700 028, India
}

Experiments were carried out to investigate the cryoprotecting potential of dextrans (ranging from 10 to $2000 \mathrm{kDa}$ ) using a synthetic model system developed recently in this laboratory. Goat spermatozoa from the cauda epididymidis were extracted in a chemically defined medium (modified Ringer's solution) and assayed for motility using a phase-contrast microscope. The sperm cells were subjected to a freezing protocol in a computercontrolled biofreezer (cooling at $0.25^{\circ} \mathrm{C} \mathrm{min}^{-1}$ to $5^{\circ} \mathrm{C} ; 5^{\circ} \mathrm{C}$ $\mathrm{min}^{-1}$ to $-20^{\circ} \mathrm{C} ; 20^{\circ} \mathrm{C} \mathrm{min}^{-1}$ to $-100^{\circ} \mathrm{C}$ ) and plunged into liquid nitrogen. The frozen cells were thawed rapidly at $37^{\circ} \mathrm{C}$ in a thermostatic waterbath. In the absence of dextran, all the spermatozoa lost their motility. The cryoprotecting efficacy of each dextran was found to be biphasic in nature. Initially, as the concentration of dextran was increased, the recovery of sperm motility also increased and reached an optimum value; however, with further increases in dextran concentration, the recovery of motility decreased sharply. Of all the sugar polymers tested, $10 \mathrm{kDa}$ dextran showed the highest cryoprotecting efficacy, whereas the $2000 \mathrm{kDa}$ sugar polymer was the least active. Dextrans of 10, 40, 73, 173, 252, 500 and $2000 \mathrm{kDa}$ offered maximum cryorecovery of forward motility to the extent of approximately $23 \%, 21 \%, 19 \%$, $18 \%, 16 \%, 15 \%$ and $8 \%$, respectively. Optimum concentrations of these dextrans for cryoprotection of sperm motility were $8.42,2.50,1.09,0.37,0.31,0.10$ and $0.04 \mathrm{mmol} \mathrm{I}^{-1}$, respectively. It thus appears that each dextran has a characteristic cryoprotection profile. The data show that the cryoprotecting efficacy and optimum cryoprotecting concentrations of dextrans are inversely related to their molecular mass. Dextran also served as a significant cryoprotectant in the presence of glycerol $(0.87$ mol $\left.^{-1}\right)$ and dimethyl sulphoxide $\left(0.76 \mathrm{~mol} \mathrm{I}^{-1}\right)$, which are well known cryoprotectants; the action of the combined cryoprotectants was almost additive. The presence of glycerol or glycerol plus dimethyl sulphoxide caused a significant reduction (from 8.42 to $6.27 \mathrm{mmol} \mathrm{l}^{-1}$ ) in the optimum concentration of dextran. In the presence of the three cryoprotectants, recovery of sperm motility was as high as $58 \%$ (forward motility) and $60 \%$ (total motility).

\section{Introduction}

A simple sperm cryopreservation model has been developed using a chemically defined medium (modified Ringer's solution; RPS) and mature goat spermatozoa from the cauda epididymidis as the model system (Kundu et al., 2000). The procedure is based on the systematic manipulation of different rates of cooling, freezing and maximum freezing temperature using a computer-controlled biofreezer. In the study of Kundu et al. (2000) highly motile sperm cells were collected from the cauda epididymides and suspended in RPS medium. The sperm preparations were cooled before storage in liquid nitrogen at various stages (from room temperature $\left(30 \pm 2^{\circ} \mathrm{C}\right.$ ) to $5^{\circ} \mathrm{C} ; 5^{\circ} \mathrm{C}$ to $-20^{\circ} \mathrm{C}$; $-20^{\circ} \mathrm{C}$ to $-100^{\circ} \mathrm{C}$ ). The cooling rate of each step was

*Correspondence

Email: majumdergc@yahoo.com optimized using glycerol as cryoprotectant. The sperm cells were highly sensitive to cooling rate, particularly during cooling from room temperature to $5^{\circ} \mathrm{C}$ and freezing from $5^{\circ} \mathrm{C}$ to $-20^{\circ} \mathrm{C}$. All the stages were important for the cryopreservation of cells. This sperm cryopreservation model is ideal for analysing the cryoprotecting potential of different reagents. Data generated using this model can be analysed easily because the medium does not contain complex substances like egg yolk, skimmed milk or milk whey. This model system has been used to study the cryoprotecting potential of several compounds, including glycerol, dimethyl sulphoxide (DMSO), ethylene glycol (Kundu et al., 2000) and different amino acids (Kundu et al., 2001). Under the optimum freezing protocol (room temperature $\left(30 \pm 2^{\circ} \mathrm{C}\right.$ ) to $5^{\circ} \mathrm{C}$ at $0.25^{\circ} \mathrm{C} \mathrm{min}^{-1} ; 5^{\circ} \mathrm{C}$ to $-20^{\circ} \mathrm{C}$ at $5^{\circ} \mathrm{C} \mathrm{min}^{-1}$; and $-20^{\circ} \mathrm{C}$ to $-100^{\circ} \mathrm{C}$ at $\left.20^{\circ} \mathrm{C} \mathrm{min}^{-1}\right)$ glycerol $\left(0.87 \mathrm{~mol} \mathrm{l}^{-1}\right)$ offered the optimum cryoprotection (recovery of total motility $35 \%$ ). The recovery of motility with DMSO $\left(1.0 \mathrm{~mol} \mathrm{l}^{-1}\right)$ and 
ethylene glycol $\left(1.29 \mathrm{~mol} \mathrm{I}^{-1}\right)$ was $20 \%$ and $13 \%$, respectively (Kundu et al., 2000). Some amino acids (for example L-alanine, glycine, L-glutamine and L-proline) offered cryoprotection (recovery of motility 10-19\%) in the range 100-150 mmol l-1. L-Alanine showed maximum efficacy (recovery of motility approximately $19 \%$ ) at $135 \mathrm{mmol} \mathrm{l}^{-1}$ (Kundu et al., 2001).

A wide variety of membrane-penetrating compounds (glycerol, ethylene glycol, DMSO, propylene glycol) are used for the preservation of spermatozoa and different types of cell (Jones, 1965; Critser et al., 1988; Watson, 1990, 1995, 2000; Abdelhakeam et al., 1991; Anchordoguy et al., 1991; Fiser et al., 1993; Maxwell and Watson, 1996; Gilmore et al., 1997, 2000; Fabbrocini et al., 2000). The addition and removal of the penetrating compounds causes potentially damaging transient osmotic stress to the cells. This problem can be circumvented by using reagents that do not penetrate the cell membrane, thus there is much interest in identifying the most efficacious non-membranepenetrating cryoprotectants. High molecular mass compounds have been tested for cryoprotecting potential for different types of cell (Ashwood-Smith et al., 1971; Schmehl et al., 1986; Sputtek et al., 1988; Phillips et al., 1996; Pellerin-Mendas et al., 1997; Singbartl et al., 1998; Henrich and Langer, 1999). Some of these compounds have the ability to protect the cell against freezing damage. Methylcellulose and hydroxyethyl starch have been used for the preservation of red blood cells (Sputtek et al., 1988; Phillips et al., 1996; Singbartl et al., 1998). Limited studies have been carried out on the preservation of sperm cells using biopolymer as the cryoprotectant. Dextran, a polymeric form of carbohydrate, has been reported as a cryoprotectant for the preservation of red blood cells (Ashwood-Smith et al., 1971; Pellerin-Mendas et al., 1997); however, few studies have been carried out on the preservation of sperm cells using dextran as cryoprotectant. In all these studies, dextran was used as a component of the complex extender (for example egg yolk) in the presence of glycerol, a well known cryoprotectant (Schmehl et al., 1986). Schmehl et al. (1986) studied the effect of a small number of dextrans of different molecular masses (15-20, 70, 200-300 kDa) and hydrolysed dextran (0.8-1.6 kDa) using TEST-yolk-glycerol and ram semen (Schmehl et al. 1986). The hydrolysed and 15-20 kDa dextran provided some cryoprotection (approximately 15-20\%) for ram sperm cells (Schmehl et al. 1986), but the other dextrans did not offer any significant cryoprotection.

The aim of the present study was to investigate systematically the cryoprotecting efficacy of dextran (of a wide range of molecular masses) using the synthetic model system developed in this laboratory.

\section{Materials and Methods}

\section{Reagents}

Inorganic salts, glucose, glycerol, DMSO and other reagents were of analytical reagent grade and were purchased from the local chemical firm (E Merck (India) Ltd, Mumbai). Plastic straws and polyvinyl chloride (PVC) powder were purchased from IMV India Limited (Gurgaon, Haryana). Penicillin G, dextran and other biochemical reagents used in the experiments were obtained from Sigma Chemical Co., St Louis, MO.

\section{Preparation of spermatozoa and epididymal plasma}

Goat epididymides were collected from local abattoirs and taken to the laboratory at atmospheric temperature. Mature goat spermatozoa were isolated from the cauda epididymides within $2-3 \mathrm{~h}$ after the animals were killed, using the procedure described by Mandal et al. (1989). Cauda epididymides were cut into small pieces which were suspended in modified Ringer's solution (RPS medium:

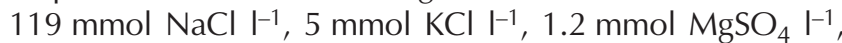

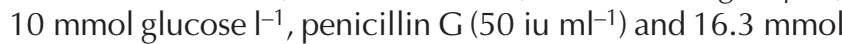
potassium phosphate $\mathrm{I}^{-1}, \mathrm{pH}$ 6.9). Spermatozoa were sedimented by gentle centrifugation at $800 \mathrm{~g}$ for $5 \mathrm{~min}$ at room temperature $\left(30 \pm 2^{\circ} \mathrm{C}\right)$ and the pellet was washed twice with RPS medium to remove contaminating epididymal plasma. The cells were dispersed in the same medium and this preparation of spermatozoa was used for the experiments. The spermatozoa in the washed cell preparation were highly motile and healthy as judged by phase-contrast microscopy. The number of spermatozoa in the sample was determined using a haemocytometer. Goat cauda epididymal plasma was prepared using the procedure described by Mandal et al. (1989). Freshly extracted sperm preparations were centrifuged at $800 \mathrm{~g}$ for $5 \mathrm{~min}$, after which most of the spermatozoa were removed as pellet. The resulting supernatants, which appeared to be slightly turbid, were centrifuged at $14000 \mathrm{~g}$ for $10 \mathrm{~min}$ to yield cell-free epididymal plasma. The concentration of the epididymal plasma was expressed as its protein content and estimated according to Lowry et al. (1951) using BSA as standard.

\section{Determination of motility}

The percentage of forward motility and total motility was assayed before freezing $\left(M_{\mathrm{b}}\right)$ (initial motility in the RPS medium before addition of cryoprotectant) and after thawing $\left(M_{\mathrm{f}}\right)$ (after removal of cryoprotectant) by the microscopic method using a haemocytometer as the counter chamber. The motility was assayed in the presence of epididymal plasma (1.2 $\mathrm{mg}$ protein $\mathrm{ml}^{-1}$ ) to eliminate the possibility of sperm adhesion to glass (Roy and Majumder, 1989). Spermatozoa $\left(0.5 \times 10^{6}\right.$ cells $)$ were incubated with epididymal plasma (0.6 mg protein) at room temperature for $1 \mathrm{~min}$ in a total volume of $0.5 \mathrm{ml}$ RPS medium. Sperm suspension $(5 \mu \mathrm{l})$ was then injected into the haemocytometer. The number of cells with forward motility (cells that moved in small or large circles were excluded) and total motility (including all types of motile cell) and the total number of cells were counted under a phase-contrast microscope at $\times 400$ magnification. The percentage of forward motility and total motility of the cells was then calculated. The per- 
centage recovery of motility was calculated by comparing motility percentages before freezing and after thawing. The percentage recovery of motility was $\left(M_{\mathrm{f}} / M_{\mathrm{b}}\right) \times 100$.

\section{Cryopreservation procedure}

Freezing. Spermatozoa were cryopreserved using the procedure reported by Kundu et al. (2000). Specified concentrations of dextran (w/v) (different molecular masses), glycerol (w/v) and DMSO (w/v) were prepared by dissolving the compounds in RPS medium. Sperm preparations were then added slowly to the cryopreservative solution such that the final concentration of the sperm cells was $60-80 \times 10^{6}$ $\mathrm{ml}^{-1}$. In each experiment, the sperm preparation contained about $35-45 \%$ forward motility and $60-70 \%$ total motility.

Cryoprotecting solutions containing sperm cells were loaded into $0.5 \mathrm{ml}$ French plastic straws. The open ends of the straws were sealed with polyvinyl chloride sealing powder. The straws were put into straw holders and placed in a programmable biofreezer (PTC-1000C, Apex Instruments, Kolkata) for freezing. The straws were cooled from room temperature $\left(30 \pm 2^{\circ} \mathrm{C}\right)$ to $5^{\circ} \mathrm{C}$ at $0.25^{\circ} \mathrm{C} \mathrm{min}^{-1}$, from $5^{\circ} \mathrm{C}$ to $-20^{\circ} \mathrm{C}$ at $5^{\circ} \mathrm{C} \mathrm{min}^{-1}$ and from $-20^{\circ} \mathrm{C}$ to $-100^{\circ} \mathrm{C}$ at $20^{\circ} \mathrm{C}$ $\mathrm{min}^{-1}$, and subsequently plunged into liquid nitrogen $\left(-196^{\circ} \mathrm{C}\right)$ for storage.

Thawing. Thawing of sperm cells was also carried out using the procedure described by Kundu et al. (2000). After $24 \mathrm{~h}$ of cryopreservation, the straws were removed from the storage cryocan and plunged immediately into a $37^{\circ} \mathrm{C}$ thermostatic waterbath for 2-3 $\mathrm{min}$ and the spermatozoa were subsequently dispersed in RPS medium. The cryoprotectants were removed from the sperm cells by washing with RPS medium by gentle centrifugation at $500 \mathrm{~g}$ for $5 \mathrm{~min}$ at room temperature. Finally, the sperm cells were resuspended in the same medium and post-thaw $\left(M_{\mathrm{f}}\right)$ motility was determined.

\section{Statistical analysis}

Results were expressed as means \pm SD. Significance tests were carried out using the Student-Newman-Keuls method and values were compared with standard tables. $P$ values of $<0.02$ were considered statistically significant.

\section{Results}

\section{Effect of dextrans on cryopreservation of spermatozoa}

This study investigated systematically the cryoprotecting potential of dextran of different molecular masses ranging from 10 to $2000 \mathrm{kDa}$ using a simple sperm cryopreservation model (Kundu et al., 2000). After freezing and thawing, both forward and total motility were lost completely when the cells were cryopreserved in the absence of dextran. All the dextrans showed characteristic cryoprotecting profiles for sperm cells. The cryoprotecting potential of each dextran was biphasic (Fig. 1). Initially, with increasing concentrations of dextran, recovery of motility increased and at particular concentrations gave maximum cryoprotection (highest recovery). However, at higher concentrations, recovery of sperm motility fell sharply. Dextran of $10 \mathrm{kDa}$ caused a concentration-dependent (2.1-8.42 $\left.\mathrm{mmol} \mathrm{I}^{-1}\right)$ increase in the recovery of both forward motility and total motility of frozen-thawed spermatozoa. Dextran of this size showed maximum cryoprotecting potential at $8.42 \mathrm{mmol} \mathrm{I}^{-1}$. At this concentration the recovery of forward motility and total motility was $23 \pm 1.5$ and $25 \pm 1.5 \%$, respectively. At higher concentrations, recovery of motility decreased sharply $(P<0.02)$. The other dextrans $(40,73,173,252,500$ and $2000 \mathrm{kDa})$ had cryoprotection profiles similar to that of $10 \mathrm{kDa}$ dextran (Fig. 1), but the optimum concentrations and maximum recovery of motility varied among the dextrans (from 10 to 24\%) (Table 1).

The highest percentage of cryoprotection (approximately $25 \%$ ) was found in the presence of $10 \mathrm{kDa}$ dextran and optimum recovery of motility decreased with increasing molecular mass of dextran. The lowest recovery (approximately $10 \%$ ) was found with $2000 \mathrm{kDa}$ dextran. Thus, it appears that the cryoprotecting potential of dextran is inversely related to its molecular mass (Fig. 2). The optimum concentration of dextran (at which maximum cryoprotection is achieved) also decreases with its increasing molecular mass, that is, lower molecular mass dextran gives maximum protection at higher concentrations (Fig. 2).

\section{Effect of dextran in combination with penetrating cryoprotectants}

Studies in this laboratory have shown that among the membrane-penetrating cryoprotectants, glycerol, at a concentration of $0.87 \mathrm{~mol} \mathrm{I}^{-1}$, provides the most effective cryoprotection (recovery of total motility approximately 35\%) (Kundu et al., 2000). Results from the present study indicate that $10 \mathrm{kDa}$ dextran offered the best cryoprotection of the range of dextrans tested (Fig. 1). Different concentrations of $10 \mathrm{kDa}$ dextran were used with 0.87 mol glycerol $\mathrm{I}^{-1}$ to increase the recovery of motility and to investigate the cryoprotection mechanism of dextran. There was a concentration-dependent $\left(2.0-6.27 \mathrm{mmol} \mathrm{I}^{-1}\right)$ increase in recovery of motility of sperm cells. The highest recovery of motility (forward motility $50 \pm 3 \%$ and total motility $53 \pm 3 \%$ ) was found at a dextran concentration of $6.27 \mathrm{mmol} \mathrm{I}^{-1}$ (Fig. 3). With further increases in the concentration of $10 \mathrm{kDa}$ dextran, the recovery of motility decreased sharply $(P<0.02)$. When different concentrations of $40 \mathrm{kDa}$ dextran were added to $0.87 \mathrm{~mol}$ glycerol $\mathrm{I}^{-1}$, there was also a concentration-dependent (0.5-2.0 mmol $\left.\mathrm{I}^{-1}\right)$ increase in the recovery of motility. The optimum cryoprotection (recovery of forward motility $45 \pm 3 \%$ and total motility

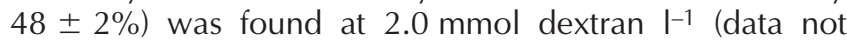
shown). These studies show that the cryoprotecting potential of dextran and glycerol is almost additive.

For the formulation of an optimum cryoprotection medium the combined effect of dextran and a mixture of 

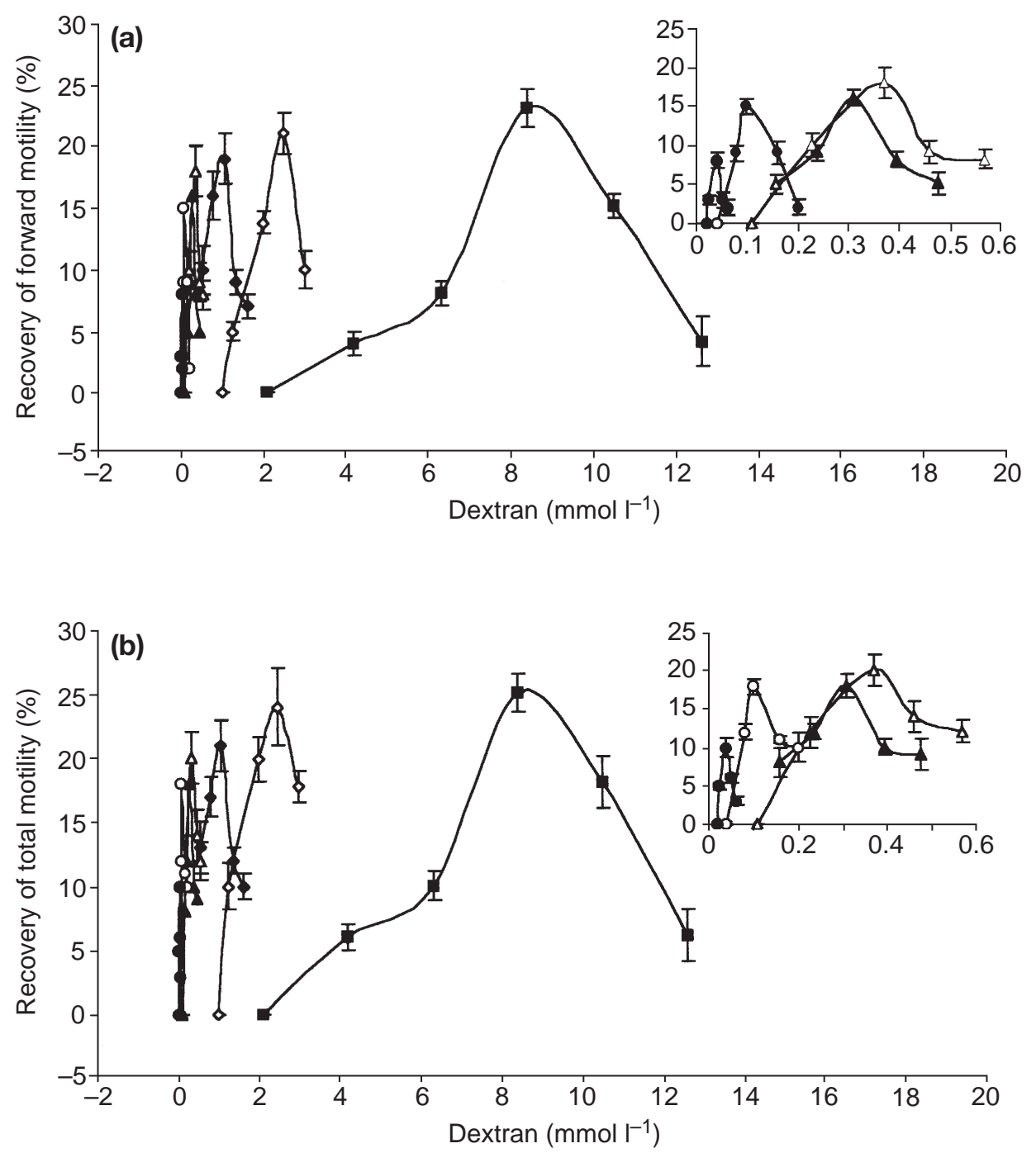

Fig. 1. Effect of various concentrations of dextran (molecular mass 10-2000 kDa) on the percentage recovery of (a) forward motility and (b) total motility of goat spermatozoa from the cauda epididymidis after freezing and thawing in the absence of other cryoprotectants: $(\boldsymbol{\square}) 10 \mathrm{kDa},(\diamond)$ $40 \mathrm{kDa},(\diamond) 73 \mathrm{kDa},(\triangle) 173 \mathrm{kDa},(\boldsymbol{\Delta}) 252 \mathrm{kDa},(\bigcirc) 500 \mathrm{kDa}$ and $(\bullet) 2000 \mathrm{kDa}$. Insets show the recovery of motility with dextrans in the range 173-2000 kDa. Values are mean \pm SD of five experiments $(P<0.02)$. The motility of sperm cells before freezing (control) was $38 \pm 3 \%$ for forward motility and $65 \pm 5 \%$ for total motility.

two membrane-penetrating compounds, glycerol and DMSO, was investigated. Kundu et al. (2001) reported that the percentage recovery of forward motility was $45 \pm 3 \%$

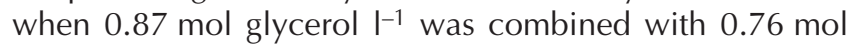
DMSO $~^{-1}$. The percentage recovery of motility increased when different concentrations of $10 \mathrm{kDa}$ dextran were used with the optimum concentrations of glycerol plus DMSO. Maximum recovery of motility (forward motility $58 \pm 3 \%$ and total motility $60 \pm 2 \%$ ) was observed at a concentration of $10 \mathrm{kDa}$ dextran of $6.27 \mathrm{mmol} \mathrm{I}^{-1}$ (Fig. 3). Another polymer of dextran (molecular mass $40 \mathrm{kDa}$ ), when added to the above optimum formulation $\left(0.87 \mathrm{~mol}^{\text {glycerol } \mathrm{I}^{-1}+}\right.$ $0.76 \mathrm{~mol}$ DMSO $\mathrm{I}^{-1}+6.27 \mathrm{mmol} \mathrm{l}^{-1}$ of $10 \mathrm{kDa}$ dextran), did not significantly increase the recovery of motility (total motility $60 \pm 2 \%$ ) (data not shown).

\section{Discussion}

Other studies on mammalian sperm cells have shown that dextran has cryoprotecting potential (Schmehl et al., 1986). In these earlier studies, the cryoprotecting efficacy of dextran was investigated in the presence of a complex extender (egg yolk). Owing to the complexity of the medium, the precise role of dextran as a cryoprotectant was uncertain. Various undefined compounds of complex media may interact with dextran and complicate the data. 
Table 1. Recovery of sperm motility and optimum concentrations for different molecular masses of dextran used as a cryoprotectant in the cryopreservation of goat spermatozoa from the cauda epididymidis

\begin{tabular}{lccr}
\hline \multirow{2}{*}{$\begin{array}{l}\text { Molecular mass of } \\
\text { dextran }(\mathrm{kDa})\end{array}$} & $\begin{array}{c}\text { Optimum concentration } \\
\left(\mathrm{mmol} \mathrm{I}^{-1}\right)\end{array}$ & \multicolumn{2}{c}{ Recovery of sperm motility $(\%)$} \\
\cline { 3 - 4 } 10 & 8.42 & $23 \pm 1.5$ & Forward motility \\
40 & 2.5 & $21 \pm 1.7$ & $25 \pm 1.5$ \\
73 & 1.09 & $19 \pm 2.0$ & $24 \pm 3.0$ \\
173 & 0.37 & $18 \pm 2.0$ & $21 \pm 2.0$ \\
252 & 0.31 & $16 \pm 1.0$ & $20 \pm 2.0$ \\
500 & 0.1 & $15 \pm 1.0$ & $18 \pm 1.5$ \\
2000 & 0.04 & $8 \pm 1.0$ & $18 \pm 1.0$ \\
\hline
\end{tabular}

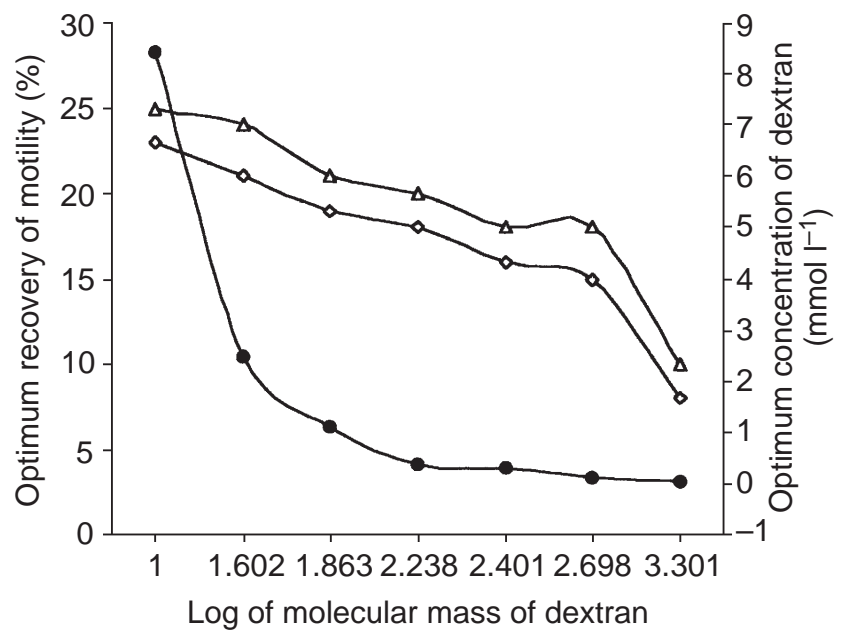

Fig. 2. Change in optimum recovery of $(\diamond)$ forward sperm motility and $(\triangle)$ total sperm motility and $(\bullet)$ optimum concentration with molecular mass of dextran. Dextran was used as a cryoprotectant in the cryopreservation of goat spermatozoa from the cauda epididymidis. Molecular mass of dextran is expressed as a logarithmic value.

The results of the present study, in which a chemically defined medium was used, demonstrate that each dextran has a characteristic biphasic curve for cryoprotection of sperm cells. Dextran of $10 \mathrm{kDa}\left(8.42 \mathrm{mmol} \mathrm{I}^{-1}\right)$ offered the most effective cryoprotection (recovery of forward motility approximately $25 \%$ ), and the lowest recovery of motility (recovery of total motility approximately $10 \%$ ) was shown by the $2000 \mathrm{kDa}$ dextran at a concentration of $0.04 \mathrm{mmol} \mathrm{I}^{-1}$. Recovery of sperm cell motility decreased with increasing molecular mass of dextran. Optimum cryoprotecting concentrations of dextrans are inversely related to the molecular mass of the sugar polymer. These results establish conclusively that dextran serves as a true cryoprotectant for a type of mammalian cell (spermatozoon).

Kundu et al. (2000) showed that the membrane-penetrating reagent glycerol, at a concentration of $0.87 \mathrm{~mol} \mathrm{I}^{-1}$, offered optimum cryoprotection (recovery of total motility
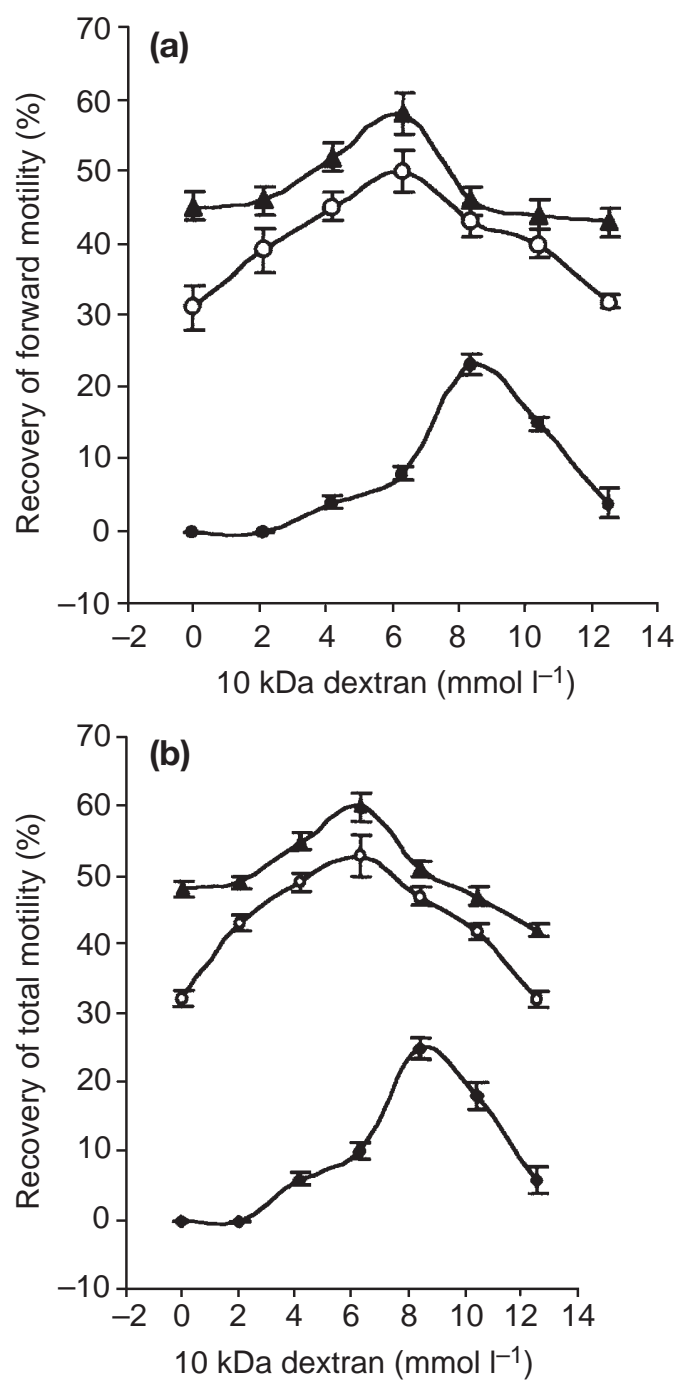

Fig. 3. Effect of various concentrations of $10 \mathrm{kDa}$ dextran on percentage recovery of (a) forward motility and (b) total motility of goat spermatozoa from the cauda epididymidis after freezing and thawing. (-) Percentage recovery of motility in the absence of other cryoprotectants; $(\bigcirc)$ percentage recover of motility in the presence of $0.87 \mathrm{~mol}_{\text {glycerol }} \mathrm{I}^{-1} ;(\mathbf{\Lambda})$ percentage recovery in the presence of $0.87 \mathrm{~mol}$ glycerol $\mathrm{I}^{-1}$ plus $0.76 \mathrm{~mol}$ dimethyl sulphoxide (DMSO) $\mathrm{I}^{-1}$. Values are mean \pm SD of five experiments $(P<0.02)$. 
$35 \%$ ) of goat spermatozoa from the cauda epididymidis. The present study shows that dextran, a non-membranepenetrating biopolymer, can also act as an efficient cryoprotectant. Furthermore, a mixture of biopolymer and glycerol provides greater cryoprotection than either of the cryoprotectants used alone at optimum concentrations. The observed, almost additive cryoprotecting efficacy of dextran and glycerol indicates that the mechanisms of action of these cryoprotectants are different. It is generally believed that the major cause of cell damage during cryopreservation is the formation of ice crystals (Mazur, 1984; Watson, 1990, 1995; Radojcic et al., 1998; Devireddy et al., 2000). It has been suggested that the cryoprotectants (for example glycerol) protect the cells by forming $\mathrm{H}$-bonds between their-OH groups and the oxygen atoms of the phospholipid head groups of the cell membrane, thereby forming a protective layer over the cell membrane that serves as a cushion for protection against ice crystals (Crowe et al., 1984, 1985; Woelders, 1997). Dextran has many -OH groups and thus may form a layer on the sperm surface by forming $\mathrm{H}$-bonds with the phosphate head groups of the membrane phospholipids. If $\mathrm{H}$-bonding is the mechanism for cryoprotection of cells, glycerol alone at an optimum concentration $\left(0.87 \mathrm{~mol} \mathrm{I}^{-1}\right)$ will offer full cryoprotection by forming $\mathrm{H}$-bonds with the inner as well as the outer cell surfaces. Furthermore, owing to the low molecular mass of glycerol and higher optimum concentration compared with dextran, this compound will out-compete dextran for the interaction with the phosphate head groups of the cell membrane. Hence, addition of biopolymer would not be expected to offer additional cryoprotection in the presence of optimum glycerol concentrations because glycerol would occupy all the free phosphate head groups of the sperm membrane via $\mathrm{H}$-bonds. It thus appears that the proposed mechanism of action of cryoprotectants through H-bonding is incorrect. Bamba and Miyagawa (1992) showed that hydrophobic aromatic compounds (for example naphthalene) serve as cryoprotectants for boar spermatozoa. These compounds act as cryoprotectants despite the fact that they are incapable of forming $\mathrm{H}$-bonds with phospholipid head groups as they do not have $-\mathrm{OH}$ groups. Furthermore, polyethylene glycol (molecular mass 600-1000 kDa), which has many-OH groups, has no cryoprotecting ability for goat sperm cells (C. N. Kundu and G. C. Majumder, unpublished). These observations are consistent with the above contention that the proposed mechanism of action of cryoprotectants via $\mathrm{H}$-bonding is incorrect.

As indicated above, glycerol and dextran cryoprotect the sperm cells by two different mechanisms, the biochemical basis of which is not clear. During freezing, ice crystals are formed. Ice crystals that form in the cytoplasm of spermatozoa are thought to damage the plasma membrane, thereby causing cell death (Mazur, 1984; Watson, 1990, 1995; Radojcic et al., 1998; Devireddy et al., 2000). Ice crystal formation is believed to occur in a number of steps: firstly unit ice crystals form and these eventually associate to give rise to large crystals (Luyet and Rapatz, 1958; Hobbs, 1974; Angel, 1982; Dupuy et al., 1982). During the formation of a unit ice crystal lattice structure, five water molecules bond via $\mathrm{H}$-bonds to form a tetrahedral arrangement (Luyet and Rapatz, 1958; Hobbs, 1974; Angel, 1982; Dupuy et al., 1982). The unit ice crystals join together through $\mathrm{H}$-bonds to form large ice crystals. Cryoprotectants may interfere with the formation of ice crystals and thereby protect the cells from ice crystal-mediated cell damage. Glycerol $\left(0.87 \mathrm{~mol} \mathrm{I}^{-1}\right)$, which offers optimum cryoprotection of the sperm cells (Kundu et al., 2000), may interfere with the formation of unit ice crystals by competing with the water molecules of the tetrahedral structure, resulting in the formation of distorted rather than well-defined unit ice crystals. Glycerol may also mechanically obstruct the formation of the tetrahedral arrangement of the water molecules during cooling. Owing to the large excess of water molecules compared with glycerol molecules in the cryoprotecting medium, glycerol-mediated inhibition of unit ice crystal formation will only be partial. As the unit crystals are essential for the formation of large ice crystals, glycerol will cause partial inhibition of the formation of large ice crystals. Glycerol is a non-ionic low molecular mass substance and is able to enter sperm cells. Thus glycerol will cryoprotect the cells by inhibiting ice crystal formation within the cell as well as in the extracellular medium. The observation that glycerol, despite its presence in the inner and outer environments of the cells, protects only about $32 \%$ of cells (Kundu et al., 2000) can be explained by the proposed limited inhibitory action of the cryoprotectant on ice crystal formation. It is possible that dextrans, as a result of their high molecular mass, cause mechanical obstruction in the second phase of ice crystal formation, that is, in the formation of large ice crystals from the unit ice crystals. Dextran will not enter sperm cells because of its high molecular mass. Therefore, dextran is able to cryoprotect the cells from the damaging action of ice crystals only in the extracellular medium. Dextranmediated cryoprotection is only partial (recovery of motility approximately $10-25 \%$ ) as it cannot protect the cells from ice crystals formed intracellularly. The observed additive cryoprotecting actions of glycerol and dextran can be explained on the basis of the proposed mechanisms of action of glycerol and dextran. Sperm cells are damaged by intracellular ice crystals and by ice crystals formed in the extracellular medium, and the cryoprotectants protect the cells from the harmful effects of these crystals.

A research grant for this investigation provided by the Department of Science and Technology, Government of India, New Delhi, is gratefully acknowledged. The authors are grateful to S. K. Bhattacharya, Director of the Indian Institute of Chemical Biology, for his interest in this study.

\section{References}

Abdelhakeam AA, Graham EF and Vazquez IA (1991) Studies on the presence and absence of glycerol in unfrozen and frozen ram semen: 
fertility trials and the effect of dilution methods on freezing ram semen in the absence of glycerol Cryobiology 28 36-42

Anchordoguy TJ, Cecchini CA, Crowe JH and Crowe LM (1991) Insights into the cryoprotective mechanism of dimethyl sulphoxide for phospholipid bilayers Cryobiology 28 467-473

Angel CA (1982) Supercooled water. In Water, A Comprehensive Treatise Vol. 7, Ed. F Franks. Plenum Press, New York

Ashwood-Smith MJ, Warby C, Connor KW and Becker S (1971) Studies on the molecular weight and cryoprotective properties of polyvinyl pyrrolidone and dextran with bacteria and erythrocytes Cryobiology 8 453-464

Bamba K and Miyagawa N (1992) Protective action of aromatic compounds against cold-shock injuries in boar spermatozoa Cryobiology 29 533-536

Critser JK, Huse-Benda AR, Aaker DV, Arneson BW and Ball GD (1988) Cryopreservation of human spermatozoa. III. The effect of cryoprotectants on motility Fertility and Sterility $50314-320$

Crowe JH, Whittam MA, Chapman D and Crowe LM (1984) Interaction of phospholipid monolayers with carbohydrates Biochimica et Biophysica Acta 769 151-159

Crowe LM, Crowe JH and Chapman D (1985) Interaction with carbohydrates with dry dipalmitoyl phophatidyl choline Archives of Biochemistry and Biophysics 236 289-296

Devireddy RV, Swanlund DJ, Roberts KP, Pryor JL and Bischof JC (2000) The effect of extracellular ice and cryoprotective agents on the water permeability parameters of human sperm plasma membrane during freezing Human Reproduction 15 1125-1135

Dupuy J, Jal JF, Ferradou C, Chieux P, Wright AF, Calemczuk R and Angel CA (1982) Controlled nucleation and quasi-ordered growth of ice-crystals from low temperature electrolyte solution Nature 296 $138-140$

Fabbrocini A, Lavadera SL, Rispoli S and Sansone G (2000) Cryopreservation of seabream (Sparus aurata) spermatozoa Cryobiology 40 46-53

Fiser PS, Fairfull RW, Hansen C, Panich PL, Shrestha JN and Underhill L (1993) The effect of warming velocity on motility and acrosomal integrity of boar sperm as influenced by the rate of freezing and glycerol level Molecular Reproduction and Development 34 190-195

Gilmore JA, Liu J, Gao DY and Critser JK (1997) Determination of optimal cryoprotectants and procedures for their addition and removal from human spermatozoa Human Reproduction 12 112-118

Gilmore JA, Liu J, Woods EJ, Peter AT and Critser JK (2000) Cryoprotective agent and temperature effects on human sperm membrane permeabilities: convergence of theoretical and empirical approaches for optimal cryopreservation methods Human Reproduction 15 335-343

Henrich HA and Langer R (1999) Erythrocytes after cryopreservation with HES: molecular, structural and functional characteristics Zentralblatt fur Chirurgie 124 271-277

Hobbs PV (1974) Ice Physics Clarendon Press, Oxford

Jones RC (1965) The use of dimethyl sulphoxide, glycerol, and reconstituted skim milk for the preservation of ram spermatozoa. I. The tonicity and toxicity of dimethyl sulphoxide and reconstituted skim milk at 30 and $5^{\circ} \mathrm{C}$ Australian Journal of Biological Sciences 18 877-885

Kundu CN, Chakrabarty J, Dutta P, Bhattacharyya D, Ghosh A and Majumder GC (2000) Development of a simple sperm cryopreservation model using a chemically defined medium and goat cauda epididymal spermatozoa Cryobiology 40 117-125

Kundu CN, Das K and Majumder GC (2001) Effect of amino acids on goat cauda-epididymal sperm cryopreservation using a chemically defined model system Cryobiology 41 21-27

Lowry OH, Rosenbrough NJ, Farr AL and Randal RJ (1951) Protein measurement with the folin phenol reagent Journal of Biological Chemistry 193 268-275

Luyet B and Rapatz G (1958) Patterns of ice formation in some aqueous solutions Biodynamica 8 1-68

Mandal M, Banerjee S and Majumder GC (1989) Stimulation of forward motility of goat cauda epididymal spermatozoa by a sperm glycoprotein factor Biology of Reproduction 41 983-989

Maxwell WMC and Watson PF (1996) Recent progress in the preservation of ram semen Animal Reproduction Science 42 55-65

Mazur P (1984) Freezing of living cells. Mechanism and implication American Journal of Physics 243 C125-C142

Pellerin-Mendas ML, Marchand-Arvier M, Labrude P and Vigneron C (1997) In vitro study of the protective effect of trehalose and dextran during freezing of red blood in liquid nitrogen Cryobiology 35 173-186

Phillips JJ, Bramwell RK and Graham JK (1996) Cryopreservation of roster sperm using methyl cellulose Poultry Science 75 915-923

Radojcic L, Vukotic-Maletic V and Balint B (1998) Current knowledge on cryopreservation of spermatozoa, ovum cells and zygotes Medical Preg/ $5129-36$

Roy N and Majumder GC (1989) Purification and characterization of an antisticking factor from goat epididymal plasma that inhibits spermglass and sperm-sperm adhesion Biochimica et Biophysica Acta 991 114-122

Schmehl MK, Vazquez IA and Graham EF (1986) The effect of nonpenetrating cryoprotectant added to TEST-yolk glycerol extender on the post-thaw motility of ram spermatozoa Cryobiology 23 512-517

Singbartl K, Langer R and Henrich HA (1998) Altered membrane skeleton of hydroxyethyl starch cryopreserved human erythrocytes Cryobiology 36 115-123

Sputtek A, Singbartl G, Langer R, Schleinzer W, Henrich HA and Kühnl P (1988) Cryopreservation of red blood cells with the non-penetrating cryoprotectant hydroxyethyl starch Cryo Letters 16 283-288

Watson PF (1990) Artificial insemination and preservation of semen. In Marshall's Physiology of Reproduction Vol. 2, 4th Edn, pp 747-869 Ed. GE Lamming. Churchill Livingstone, Edinburgh

Watson PF (1995) Recent developments and concepts in the cryopreservation of spermatozoa: the assessment of their post-thawing function Reproduction, Fertility and Development 7 871-891

Watson PF (2000) The causes of reduced fertility with cryopreserved semen Animal Reproduction Science 60 481-492

Woelders H (1997) Fundamentals and recent development in cryopreservation of bull and boar semen Veterinary Quarterly 19 135-138

Received 27 November 2001.

First decision 11 January 2002.

Accepted 14 February 2002. 